\title{
Maternally transmitted isotopes and their effects on larval fish: a validation of dual isotopic marks within a meta-analysis context
}

\author{
Danswell Starrs, Jacqueline T. Davis, Jodie Schlaefer, Brendan C. Ebner, Stephen M. Eggins, \\ and Christopher J. Fulton
}

\begin{abstract}
Transgenerational marking enables mass-marking of larval fishes via transmission of enriched stable isotopes from mother to offspring, but potential impacts on the resultant progeny are poorly understood. We injected enriched stable isotopes $\left({ }^{137} \mathrm{Ba}\right.$ and $\left.{ }^{87} \mathrm{Sr}\right)$ into female purple-spotted gudgeon, Mogurnda adspersa, to produce multiple batch markers and examined larval morphology at hatch as well as survival and growth to 31 days posthatch in marked and unmarked offspring. Transgenerational marking had minimal effects on larval growth and survival, whereas body depth at hatch was significantly reduced in marked larvae. A meta-analysis of transgenerational marking effects on larval morphology at hatch and growth rates across multiple fish species found a nonsignificant positive effect of enriched stable barium isotopes on larval morphology at hatch, but a significant negative effect on growth. There were no significant effects of strontium on morphology or growth. Meta-regression analysis revealed that larval size at hatch increased with the dose of injected stable barium isotopes, but this result should be interpreted cautiously. Because of high levels of between-study heterogeneity, we caution against assuming there are no effects of transgenerational marking on fish offspring; any such effects should be validated and incorporated into transgenerational marking studies of fish dispersal.
\end{abstract}

Résumé : Si la méthode de marquage transgénérationnel permet le marquage d’un grand nombre de larves de poisson par la transmission d'isotopes stables enrichis de la mère à sa progéniture, ses impacts potentiels sur cette progéniture demeurent mal compris. Nous avons injecté des isotopes stables enrichis $\left({ }^{137} \mathrm{Ba}\right.$ et $\left.{ }^{87} \mathrm{Sr}\right)$ dans une femelle de Mogurnda adspersa pour produire différents marqueurs de lot et avons examiné la morphologie, la survie et la croissance de larves marquées et non marquées 31 jours après leur éclosion. Si le marquage transgénérationnel a eu peu d'effets sur la croissance et la survie des larves, la profondeur du corps au moment de l'éclosion était significativement plus faible pour les larves marquées. Une méta-analyse des effets du marquage transgénérationnel sur la morphologie des larves à l'éclosion et les taux de croissance pour différentes espèces de poisson a révélé un effet positif non significatif sur la morphologie des larves à l'éclosion, mais un effet négatif significatif sur la croissance, attribuable à l'enrichissement des isotopes stables de baryum. Aucun effet significatif du strontium sur la morphologie ou la croissance n’a été décelé. L'analyse de méta-régression a révélé que la taille des larves à l'éclosion augmentait parallèlement à la dose d'isotopes stables de baryum injectée, mais ce résultat devrait être interprété avec prudence. En raison des degrés élevés d'hétérogénéité entre les études, il est recommandé de ne pas présumer que le marquage transgénérationnel n’a aucun effet sur la progéniture de poisson, la présence de tels effets devant préalablement être validée, puis incorporée dans les études sur la dispersion des poissons reposant sur le marquage transgénérationnel. [Traduit par la Rédaction]

\section{Introduction}

Fish movement has often been studied using techniques that apply identifiable marks on individuals, such as visible external tags and radio-tags (Woodbury et al. 1956; Cooke et al. 2013). Unfortunately, many of these techniques, and particularly those reliant on physical tags (e.g., dart tags, many telemetry tags), often have restricted longevity (due to tag loss or battery life) and cannot be applied to fish below certain body size thresholds because they compromise the movement, behaviour, and (or) physiology of individuals. More recently, a range of techniques for marking otoliths, scales, and bones have been developed to mass-mark fish (e.g., thermal marking; Volk et al. 1999). In a landmark study, orange clownfish (Amphiprion percula) were mass-marked with tetracycline during the egg phase to successfully reveal natal homing in larvae and overturn the long-held paradigm of open population dynamics in coral reef fishes (Jones et al. 1999, 2009). Since this landmark study, mass-marking of fish larvae has been achieved via immersion of larvae in solutions of enriched stable isotopes of barium (Munro et al. 2008; Woodcock et al. 2011) and strontium (Woodcock et al. 2011) and via dietary transfer with feeds containing enriched barium isotopes in hatchery facilities (Woodcock et al. 2013). Likewise, the natural geochemical signatures in otoliths of fishes have been repeatedly used to demonstrate closed population dynamics in a range of coral reef species (Swearer et al.

Received 1 August 2013. Accepted 6 November 2013.

Paper handled by Associate Editor Bronwyn Gillanders.

D. Starrs, J.T. Davis, and J. Schlaefer. Evolution, Ecology \& Genetics, Research School of Biology, The Australian National University, Canberra, ACT 0200, Australia.

B.C. Ebner. CSIRO Ecosystem Sciences, Atherton, QLD 4883, Australia, and TropWATER, James Cook University, Townsville, QLD 4811, Australia. S.M. Eggins. Research School of Earth Sciences, The Australian National University, Canberra, ACT 0200, Australia.

C.J. Fulton. Evolution, Ecology \& Genetics, Research School of Biology, The Australian National University, Canberra, ACT 0200, Australia; ARC Centre of Excellence for Coral Reef Studies, Research School of Biology, The Australian National University, Canberra, ACT 0200, Australia.

Corresponding author: Danswell Starrs (e-mail: danswell.starrs@anu.edu.au). 
1999; Jones et al. 2009). Notwithstanding these advances, logistical constraints lead to low recapture rates of recruits when applying standard immersion marking techniques (Jones et al. 1999). Furthermore, limited spatial resolution can restrict the effectiveness of natural otolith geochemistry techniques (Berumen et al. 2010; Pangle et al. 2010). Therefore, in many cases a lowcost and highly efficient artificial marking technique that can detect spatial fidelity at small scales and dispersal of larvae by marking large numbers of early life history phase individuals en masse is desirable.

Transgenerational marking is a new technique for massmarking the offspring of female fish; it involves injecting the maternal source with an enriched stable isotope of either barium or strontium (Thorrold et al. 2006; Zitek et al. 2013). The enriched stable isotope is transmitted into the egg and then incorporated into the otoliths of the developing larva. Owing to the inert nature of otoliths, the enriched isotope remains within the core region of the otolith indefinitely, effectively marking an individual permanently. Previous studies have shown that after being injected, females may continue to produce marked offspring for more than 3 months (Thorrold et al. 2006; Huelga-Suarez et al. 2012). Transgenerational marking has been successfully used in the wild to examine larval dispersal of clownfish and butterflyfish in coral reef ecosystems (Almany et al. 2007). Multiple studies have also validated the efficacy of the technique as a marking tool while exploring the impacts of the technique on both the female fish injected (Williamson et al. 2009b; Roy et al. 2013) and the subsequent progeny produced (Williamson et al. 2009a; Zitek et al. 2013). These previous studies have attempted to elucidate whether minute quantities of enriched stable isotopes have toxic effects on larval size and growth (Williamson et al. 2009a; Zitek et al. 2013) or pose a threat to human health after consumption of injected fish (Williamson et al. 2009b). Many of these studies have used a single isotopic marker. However, to date, the effects of transgenerational marking on the traits of marked larvae have not been evaluated.

In the present study, we determined whether a combination of enriched barium and strontium isotopes could be injected into females of the tropical freshwater purple-spotted gudgeon, Mogurnda adspersa (Castelnau, 1878), to create multiple unique batch markers in subsequent offspring. We then examined the effect of transgenerational marking on day-of-hatch larval morphology, as well as growth and survivorship to 31 days posthatch. We also conducted a meta-analysis to explore transgenerational marking effects on larval morphology and growth, drawing from studies of eight species over the past 7 years. Our meta-analysis allowed us to identify areas of concern and future priorities for both laboratory and field-based applications of transgenerational marking.

\section{Methods and materials}

\section{Fish husbandry and isotope injection}

Adult M. adspersa were held in $62 \mathrm{~L}$ aquaria in the laboratory (Canberra, Australia) for the duration of the experiment. Water temperature and day length were maintained at $25.5^{\circ} \mathrm{C}$ and $13 \mathrm{~h}$ light : $11 \mathrm{~h}$ dark. Fish were fed once daily on frozen bloodworms (Chironomidae) and once weekly on raw prawns (Penaeidae). Mogurnda adspersa are batch spawners, and females can produce up to $\sim 1300$ eggs per clutch in weekly spawnings (Pusey et al. 2004). After spawning, males guard the eggs for $\sim 5$ days until they hatch. Newly hatched larvae were fed a combination of finely ground fish flakes (Kongs Australia Pty Ltd., Sydney) and newly hatched brine shrimp (Artemia salina). By 5 days posthatch, the majority of fish larvae fed upon baby A. salina.

Adult females (14.5 $\pm 1.3 \mathrm{~g}$ standard error $(\mathrm{SE})$, range $=7.9-27.1 \mathrm{~g}$, $n=16$ ) were injected with enriched stable isotopes or a saline control solution for this experiment. Females were split into two groups based on mass (large, $18.2 \pm 1.54 \mathrm{~g}, n=8$; small, $10.8 \pm 0.93 \mathrm{~g}, n=8$ ) and then randomly assigned to treatments ( $n=4$ per treatment) to ensure a similar range of female sizes in each treatment. Females were fasted for $\sim 36 \mathrm{~h}$ prior to injection to reduce gut fullness and the risk of internal injuries from injection. Each fish was weighed to the nearest $0.1 \mathrm{~g}$ and injected with a dose of $20 \mu \mathrm{g} \cdot \mathrm{g}^{-1}$ body mass of enriched (81.9\% enrichment) ${ }^{137} \mathrm{Ba}\left({ }^{137} \mathrm{Ba}\right.$ treatment), $20 \mu \mathrm{g} \cdot \mathrm{g}^{-1}$ body mass of enriched (91.3\% enrichment) ${ }^{87} \mathrm{Sr}$ ( ${ }^{87} \mathrm{Sr}$ treatment), a combined solution of both isotopes delivering a dose of $20 \mu \mathrm{g} \cdot \mathrm{g}^{-1}$ of each isotope $\left({ }^{137} \mathrm{Ba}+{ }^{87} \mathrm{Sr}\right.$ treatment), or a $0.1 \mathrm{~g} \cdot \mathrm{mL}^{-1}$ saline solution (control) with the quantity being equivalent to a ${ }^{137} \mathrm{Ba}$ injection. Fish were injected in the visceral cavity anterior to the urogenital opening with a 31 gauge needle and $1 \mathrm{~mL}$ syringe before being returned to their aquaria to recover. All females were observed to be feeding $48 \mathrm{~h}$ postinjection with no mortalities. Seven days postinjection, females were placed into aquaria with their respective males to spawn, whereupon all pairs spawned within 4 days.

Females were removed immediately postspawning, leaving males to guard the eggs. Three clutches of eggs (two from the control group and one from the ${ }^{137} \mathrm{Ba}$ treatment group) produced relatively few larvae ( $<10$ larvae each), so the spawning of both control females with males was repeated 10 days later. Both of these spawnings were successful (i.e., controls produced sufficient larvae). One female from the ${ }^{137} \mathrm{Ba}$ treatment was not spawned again owing to poor condition. From each parental pair (15 pairs in total), 45 larvae were collected from day of hatch to 12 days posthatch for morphological analysis, growth and survival experiments, and otolith isotope analysis (described below).

\section{Larval morphology, survival, and growth}

Ten larvae were collected from each parental pair within $12 \mathrm{~h}$ of hatching for morphological analysis. An additional 10 larvae were also examined from clutches produced by each pair 63-133 days prior (one clutch 233 days prior) to injection with enriched stable isotopes or saline solution, for comparison, with the exception of two pairs (one each from the ${ }^{137} \mathrm{Ba}$ and ${ }^{87} \mathrm{Sr}$ treatments). Each larvae was photographed on a $10 \mathrm{~mm}$ stage micrometer under a dissecting microscope (Leica-Wild MZ8; Leica GmbH Wetzlar, Germany) fitted with a 6 MP digital camera. Each larva was photographed three times. Images were analysed in ImageJ (version 1.44; Abràmoff et al. 2004). Standard length (SL), eyeball diameter, and body depth were measured from each image for each larvae $( \pm 0.01 \mathrm{~mm})$, and for each trait an average of the three measurements was used in subsequent analyses.

Twenty-four hours posthatch, 30 larvae were randomly collected from each aquarium and transferred to $5 \mathrm{~L}$ tubs for rearing. The larvae rearing system has been described previously (Starrs et al. 2013) but was modified for the present study. Forty-eight clear plastic $5 \mathrm{~L}$ tubs were arranged in a row-column design on two racks ( 24 tubs per rack) in a light- and temperature-controlled room (13 h light : $11 \mathrm{~h}$ dark and $27.1 \pm 0.5{ }^{\circ} \mathrm{C} \mathrm{SE}$ ). Tubs were arranged to evenly balance treatments across racks, rows, and columns to minimize any possible influence of tub placement while allowing for the detection of such effects. Ten larvae (in two tubs, $n=11$ ) were placed into each tub so as to stratify females across racks, rows, and columns. Larvae were reared until 31 days of age. Larvae were fed twice daily with $0.2 \mathrm{~mL} \cdot \mathrm{day}^{-1}$ of finely ground fish flakes (days 1-4), and then newly hatched A. salina were added to the crushed flakes (days 5-8) until larvae could be fed solely with baby $A$. salina until the end of the experiment (days 9-31). The density of baby A. salina was $1425 \pm 183.7 \mathrm{~mL}^{-1}(n=6)$. The rate of feeding by the fish larvae on newly hatched $A$. salina at 9 days was $0.30 \mathrm{~mL} \cdot$ day $^{-1}$, and at 31 days was $1.0 \mathrm{~mL} \cdot$ day $^{-1}$. Food was increased as necessary to ensure satiation of the fish larvae, as indicated by some excess food being present in the tubs $30 \mathrm{~min}$ postfeeding. Each morning, larvae were counted in each tub, and 
observed dead larvae were removed. On day 31, fish were removed from tubs, euthanized in ice-water slurry, and preserved in $70 \%$ ethanol. Each juvenile was photographed three times with a dissecting microscope as described above. Total length (TL, mm) was measured three times and averaged for subsequent analyses. TL was measured instead of SL because it was difficult to confidently locate the end of the hypural plates at all developmental stages. We ensured there was no significant caudal fin damage that could affect TL comparisons among and within treatments.

\section{Otolith preparation and isotope analysis}

One sagittal otolith was extracted from each of five larvae collected from each aquarium 8-12 days posthatch, yielding a total of 80 otoliths for laser ablation inductively coupled plasma mass spectrometry (LA-ICPMS). Larvae of this age were chosen because the otoliths are easily handled and require minimal preparation for LA-ICPMS. Otoliths were dissected from each fish with fine needles and tweezers and cleaned of adhering tissue, then mounted sulcus side up onto a microscope slide using nail polish (Rimmel 740, Coty Inc., London) for laser ablation.

Otolith isotope ratios were measured via LA-ICPMS with a Varian 820 ICPMS coupled to a Lambda Physik Compex 110i ArF Excimer $193 \mathrm{~nm}$ laser (described in Eggins et al. 2004). Otoliths were vertical depth profiled with a $30 \mu \mathrm{m}$ diameter laser spot with an energy density of 5-10 J.cm $\mathrm{cm}^{-2}$, pulsed at $3 \mathrm{~Hz}$. The laser was focused on the exterior surface above the core of the sagittal otolith. Vertical depth profiling was conducted through the entire otolith. Isotope ratios of ${ }^{43} \mathrm{Ca},{ }^{44} \mathrm{Ca},{ }^{55} \mathrm{Mn},{ }^{87} \mathrm{Sr},{ }^{88} \mathrm{Sr},{ }^{137} \mathrm{Ba}$, and ${ }^{138} \mathrm{Ba}$ were collected consecutively, with a $30 \mathrm{~ms}$ dwell time. An instrumental blank was collected at the beginning and end of each set of $\sim 25$ otoliths, as was a $60 \mathrm{~s}$ sample of an aluminosilicate glass (NIST 610) and aragonite coral standard. Background subtraction and correction for instrumental drift were made using standard techniques. Counts-per-second data were converted to parts per million using the NIST 610 glass as a reference. A 5-point running average was applied to the data to reduce counting statistic and plasma noise (Sinclair et al. 1998) before calculating ${ }^{138} \mathrm{Ba} /{ }^{137} \mathrm{Ba}$ and ${ }^{88} \mathrm{Sr} /{ }^{87} \mathrm{Sr}$ ratios. Correction for instrument bias was applied to the coral standard reference data to calibrate ${ }^{138} \mathrm{Ba} /$ ${ }^{137} \mathrm{Ba}$ and ${ }^{88} \mathrm{Sr} /{ }^{87} \mathrm{Sr}$ to natural isotope ratios as specified in Rosman and Taylor (1998). The natural ${ }^{138} \mathrm{Ba} /{ }^{137} \mathrm{Ba}$ isotope ratio is 6.38 (Rosman and Taylor 1998), while normalization to local ${ }^{87} \mathrm{Sr} /{ }^{86} \mathrm{Sr}$ produced a natural ${ }^{88} \mathrm{Sr} /{ }^{87} \mathrm{Sr}$ isotope ratio of 11.5 (Roddick and Compston 1977).

From each otolith, data that corresponded to a peak in ${ }^{55} \mathrm{Mn}$ were selected for analysis, as this peak has been reported to correspond with the otolith core in many fish species (Brophy et al. 2004; Macdonald et al. 2008; Munro et al. 2009). Twenty-five data points (corresponding to $\sim 9 \mathrm{~s}$ of analysis time) were selected around the peak ${ }^{55} \mathrm{Mn}$ value, following Starrs et al. (in press), and corresponded to $60 \%$ of the width of the ${ }^{55} \mathrm{Mn}$ spike. For otoliths that did not display a pronounced ${ }^{55} \mathrm{Mn}$ spike $(n=18), 25$ data points were selected $45 \%$ of the way through the otolith ablation record, which corresponded to the average position of the ${ }^{55} \mathrm{Mn}$ spike in the 62 otoliths that displayed a ${ }^{55} \mathrm{Mn}$ spike. Mean \pm standard deviation (SD) ${ }^{138} \mathrm{Ba} /{ }^{137} \mathrm{Ba}$ and ${ }^{88} \mathrm{Sr} /{ }^{87} \mathrm{Sr}$ ratios were calculated from each otolith. One otolith from the ${ }^{137} \mathrm{Ba}$ treatment group showed an isotope signature characteristic of a fish from the ${ }^{87} \mathrm{Sr}$ treatment group; this was attributed to human error during otolith preparation and the otolith was therefore excluded from further analysis.

\section{Statistical analysis}

Linear mixed effects models were used to explore the effects of transgenerational marking on day-of-hatch larval morphology. Treatment (four levels: control, ${ }^{137} \mathrm{Ba},{ }^{87} \mathrm{Sr}$, and ${ }^{137} \mathrm{Ba}+{ }^{87} \mathrm{Sr}$ ) and clutch (two levels: preinjection and postinjection) were included as fixed factors, while female identity was included as a random factor. Mixed effects models were used to explore the effects of treatment on day-of-hatch data with regard to SL, eyeball diameter, and body depth. Proportion of variance $\left(P_{\mathrm{V}}\right)$ attributed to the random factor was calculated as

$$
P_{\mathrm{V}}=V_{\mathrm{r}}\left(V_{\mathrm{r}}+V_{\mathrm{fe}}\right)^{-1}
$$

where $V_{\mathrm{r}}$ is the variance explained by the random factor, and $V_{\mathrm{fe}}$ is the residual variance, which includes the variance explained by the fixed factors and the residual error (Nakagawa and Schielzeth 2010). Significant differences in variance of SL, eyeball diameter, and body depth of larvae before and after injection were explored with paired Levene tests. The effect of female body mass (g) on larval length, eyeball diameter, and body depth at hatch was explored with linear regression on both preinjection and postinjection larvae. Additionally, we examined whether the time (days) between preinjection and postinjection clutch collection influenced the difference in trait means between preinjection and postinjection larvae. Juvenile TL from the larval growth and survival experiment was also explored in a mixed effects model framework. Treatment was included as a fixed factor, while tub, nested within female identity, was included as a random factor. Significance of factors in linear mixed effects models was examined by analyses of deviance (type II Wald tests) in $\mathrm{R}$ with the package "car" (version 2.0-19; Fox et al. 2013). A three-way ANOVA was used to explore the effects of rack, row, and column on growth. A Levene test was used to explore variance in TL between treatment groups. Survivorship between treatments was examined with an exploratory survival analysis to account for the high degree of right censoring (survival to 31 days of age) (Harrell 2001). Kaplan-Meier survival curves with 95\% confidence intervals were produced, while a mixed effects Cox proportional hazards model (package "coxme", version 2.2-3; Therneau 2012), with treatment as a fixed effect and tub nested within female as a random effect, was used to examine differences in survival among treatments.

Otolith isotope ratios from the ${ }^{137} \mathrm{Ba},{ }^{87} \mathrm{Sr}$, and ${ }^{137} \mathrm{Ba}+{ }^{87} \mathrm{Sr}$ treatment groups were defined as being significantly spiked if ${ }^{138} \mathrm{Ba} /$ ${ }^{137} \mathrm{Ba},{ }^{88} \mathrm{Sr} /{ }^{87} \mathrm{Sr}$, and ${ }^{138} \mathrm{Ba} /{ }^{137} \mathrm{Ba}+{ }^{88} \mathrm{Sr} /{ }^{87} \mathrm{Sr}$ ratios were two standard deviations less than the respective means of the 20 control otoliths (sensu Munro et al. 2008). Data reduction was conducted offline in Microsoft Excel 2007, and data analysis was conducted in $\mathrm{R}$ (version 2.13; R Development Core Team 2011) with the package "lme4" (version 0.999; Bates et al. 2011). Figures were prepared in Sigmaplot (version 10; Systat Software Inc., London).

\section{Meta-analysis of transgenerational marking effects}

To place our findings in the context of previous transgenerational marking studies, we conducted a meta-analysis on the impacts of transgenerational marking on fish larvae. We conducted searches in Google Scholar, Scopus, and Web of Science for published and unpublished manuscripts that cited the seminal study describing transgenerational marking (Thorrold et al. 2006), netting a total of 88 papers (search conducted 1 June 2013). These papers were screened for suitable studies for the meta-analysis, defined a priori as those that (i) examined a trait or traits likely to be related to larval fitness after females had been injected with an enriched stable isotope or element and (ii) had clearly defined sample sizes and a control group. We excluded 81 papers that were ineligible according to these criteria, leaving six papers for inclusion in the meta-analysis. To these we added the current study and Starrs et al. (in press) to yield a total of eight studies spanning eight species for the meta-analysis. Details of the data 
collection and meta-analysis are provided elsewhere (see online Supplementary Information). ${ }^{1}$

We conducted four separate meta-analyses on the following: (i) the effect of injected enriched stable barium isotopes on morphological traits at hatch, (ii) the effect of injected strontium (both enriched stable isotopes and strontium chloride, $\mathrm{SrCl}_{2}$ ) on morphological traits at hatch, (iii) the effect of injected enriched stable barium isotopes on larval growth rates, and (iv) the effect of injected strontium (both enriched stable isotopes and $\mathrm{SrCl}_{2}$ ) on larval growth rates. We made the assumption that the impacts of barium and strontium may differ, while any impacts of enriched stable strontium isotopes and $\mathrm{SrCl}_{2}$ would be identical. For each of the four meta-analyses we also conducted a meta-regression to assess whether the effect size varied according to dose $\left(\mu \mathrm{g} \cdot \mathrm{g}^{-1}\right)$ of injected isotopes or $\mathrm{SrCl}_{2}$, and for analysis of growth effects, larval age (days) at time of growth measurement was also included. We used random-effects models with inverse-variance weights, implemented in $\mathrm{R}$ with the packages "compute.es" (version 0.2.1; Del Re 2012) and "metafor" (version 1.7-0; Viechtbauer 2010) (see Supplementary Information 1). ${ }^{1}$ Diagnostic and sensitivity analyses were conducted after each analysis to explore the robustness of findings.

\section{Results}

Isotopic marking and larval morphology, survival, and growth in Mogurnda adspersa

Day-of-hatch larvae differed in their response to transgenerational marking in terms of the three morphological traits measured among clutches collected pre- and postinjection (Fig. 1). There were no significant differences in SL at hatch among treatment groups or between pre- and postinjection clutches (Table 1, Fig. 1a). There was a significant decline in eyeball diameter postinjection (Table 1) but this was shared equally across all treatments and the postinjection control, indicating that transgenerational marking was not the cause of this morphological change (Fig. 1b). Notably, larvae from the ${ }^{87} \mathrm{Sr}$ and ${ }^{137} \mathrm{Ba}+{ }^{87} \mathrm{Sr}$ treatments displayed significantly greater body depths than the control treatment group, preinjection (Table 1, Fig. 1c). Postinjection, there was a nonsignificant decrease in body depth in the control larvae, but larvae from all three enriched stable isotope injection groups showed significant decreases in body depth (Table 1), with the ${ }^{87} \mathrm{Sr}$ treatment group showing the greatest reduction in body depth (Fig. 1c). Maternal identity was an important source of variation, with the random factor $\left(P_{\mathrm{V}}\right)$ explaining $68 \%, 68 \%$, and $44 \%$ of the variation in SL, eyeball diameter, and body depth, respectively (Table 1). However, female body mass did not have any significant effects on either preinjection or postinjection larval length, eyeball diameter, or body depth (all $P$ values $>0.05$ ). Similarly, there were no significant effects of time between pre- and postinjection clutch collection on larval length, eyeball diameter, or body depth (all $P$ values $>0.05$ ). No significant differences in variance between preinjection and postinjection larvae were detected for SL and eyeball diameter $\left(F_{[1,299]}=3.14, P=0.07\right.$ and $F_{[1,299]}=1.34, P=0.25$, respectively); however, there was a significant decrease in variance for body depth, pre- to postinjection $\left(F_{[1,299]}=7.81, P=0.005\right)$, with variance postinjection being reduced by $43 \%, 24 \%$, and $55 \%$ for the control, ${ }^{87} \mathrm{Sr}$, and ${ }^{137} \mathrm{Ba}+{ }^{87} \mathrm{Sr}$ treatment groups, respectively. Conversely, variance increased $59 \%$ in the ${ }^{137} \mathrm{Ba}$ treatment group, pre- to postinjection. The average reduction across all four treatment groups was $40 \%$.

Survival in the rearing experiment was high: 404 of 452 (89.4\%) larvae survived to 31 days posthatch, with the majority of deaths occurring in the control group (Fig. 2). Mortality was equally shared across all three enriched stable isotope groups, with six,
Fig. 1. Mean $\pm 95 \%$ confidence intervals $(\mathrm{mm})$ of $(a)$ standard length, (b) eyeball diameter, and (c) body depth of day-of-hatch M. adspersa larvae collected before injection (dark bars) and after injection (light bars) of females with ${ }^{137} \mathrm{Ba},{ }^{87} \mathrm{Sr},{ }^{137} \mathrm{Ba}+{ }^{87} \mathrm{Sr}$, or a saline control.
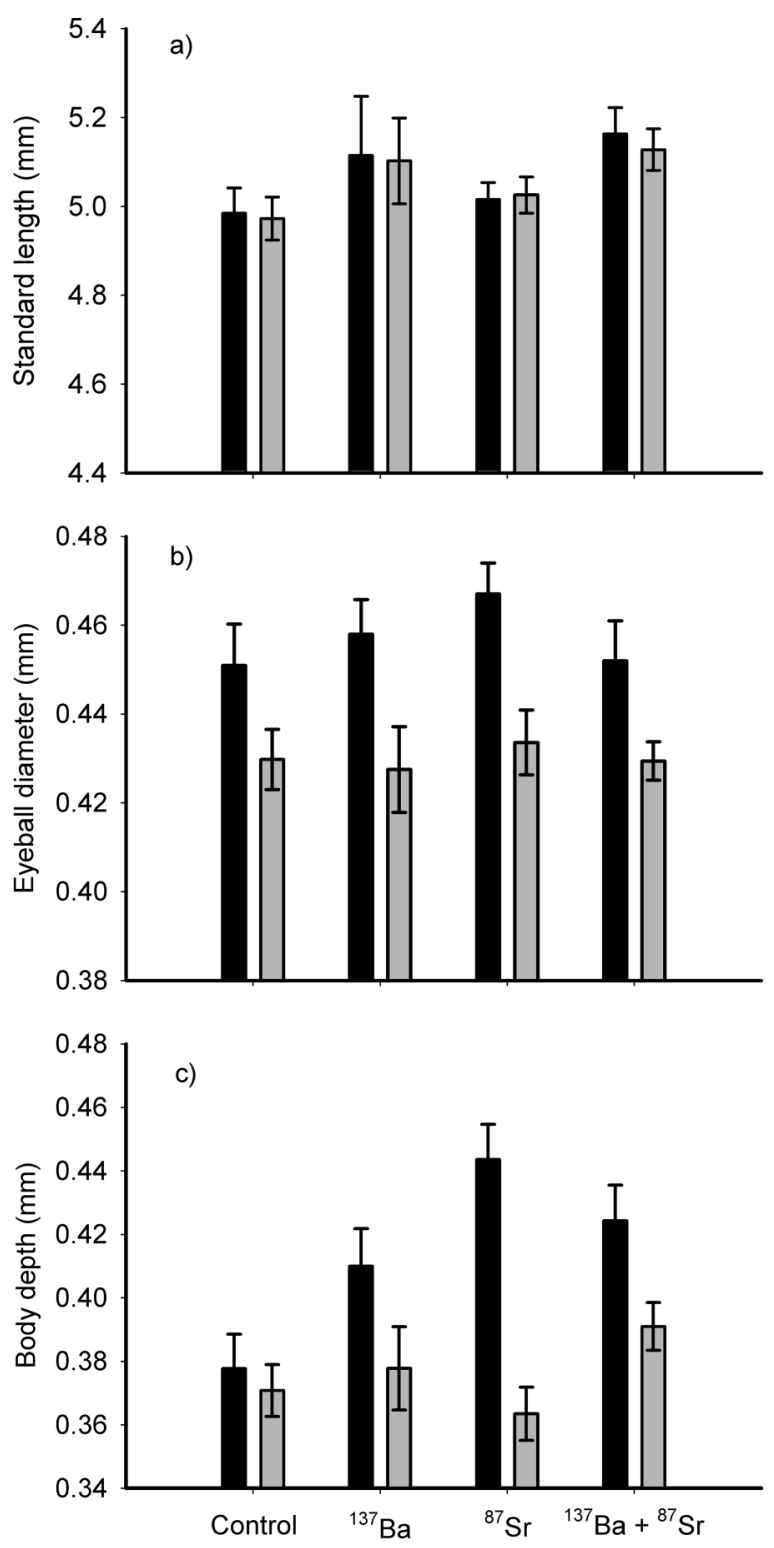

nine, and seven deaths in the ${ }^{137} \mathrm{Ba},{ }^{87} \mathrm{Sr}$, and ${ }^{137} \mathrm{Ba}+{ }^{87} \mathrm{Sr}$ treatment groups, respectively. Conversely, 26 deaths occurred in the control group, primarily in two tubs from two separate females that lost seven larvae each. There were no significant effects of rack, row, or column on TL or mortality rates. A mixed effects Cox proportional-hazards model found a nonsignificant effect of treatment on survivorship (Table 2). Most deaths occurred in the first 15 days of the experiment, with just a single death occurring after 15 days posthatch (Fig. 2). After 31 days, TL of juvenile M. adspersa was $11.68 \pm 0.06 \mathrm{~mm}$ (range: 7.61-14.66 $\mathrm{mm}$ ), with variance in TL not significantly different among treatment groups $\left(\mathrm{F}_{[3,398]}=1.32\right.$, $P=0.27$ ). There was no significant effect of treatment on TL of juveniles after 31 days of growth (Table 3, Fig. 3), and the random effect of "tub" nested within "maternal identity" explained just $9 \%$ of the observed variation $\left(P_{\mathrm{V}}\right)$ in TL (Table 3).

${ }^{1}$ Supplementary data are available with the article through the journal Web site at http://nrcresearchpress.com/doi/suppl/10.1139/cjfas-2013-0416. 
Table 1. Linear mixed effects models of standard length, eyeball diameter, and body depth of day-of-hatch M. adspersa larvae collected before and after injection (Clutch) of females with $20 \mu \mathrm{g} \cdot \mathrm{g}^{-1}$ of ${ }^{137} \mathrm{Ba},{ }^{87} \mathrm{Sr},{ }^{137} \mathrm{Ba}+{ }^{87} \mathrm{Sr}$, or a saline control (Treatment).

\begin{tabular}{|c|c|c|c|c|c|c|c|c|c|}
\hline \multirow[b]{2}{*}{ Fixed factor } & \multicolumn{3}{|c|}{ Standard length } & \multicolumn{3}{|c|}{ Eyeball diameter } & \multicolumn{3}{|c|}{ Body depth } \\
\hline & $\mathrm{df}$ & $\chi^{2}$ & $P$ & df & $\chi^{2}$ & $P$ & $\mathrm{df}$ & $\chi^{2}$ & $P$ \\
\hline Clutch & 1 & 1.06 & 0.30 & 1 & 119.2 & $<0.001$ & 1 & 113.1 & $<0.001$ \\
\hline Treatment & 3 & 1.71 & 0.64 & 3 & 0.25 & 0.97 & 3 & 4.21 & 0.24 \\
\hline Clutch $\times$ Treatment & 3 & 7.18 & 0.07 & 3 & 1.09 & 0.78 & 3 & 70.05 & $<0.001$ \\
\hline Random factor & \multicolumn{3}{|c|}{ Variance } & \multicolumn{3}{|c|}{ Variance } & \multicolumn{3}{|c|}{ Variance } \\
\hline ID & \multicolumn{3}{|c|}{0.038} & \multicolumn{3}{|c|}{$5.40 \mathrm{E}-04$} & \multicolumn{3}{|c|}{$5.20 \mathrm{E}-04$} \\
\hline Residual & \multicolumn{3}{|c|}{0.018} & \multicolumn{3}{|c|}{$2.60 \mathrm{E}-04$} & \multicolumn{3}{|c|}{ 6.75E-04 } \\
\hline
\end{tabular}

Note: $\chi^{2}$ statistics are type II Wald tests of analysis of deviance. Bold $P$ values indicate statistical significance $(P \leq 0.05)$.

Fig. 2. Kaplan-Meier survival curves (solid lines) $\pm 95 \%$ confidence intervals (dashed lines) for juvenile M. adspersa from females injected with (a) ${ }^{137} \mathrm{Ba},(b){ }^{87} \mathrm{Sr},(c){ }^{137} \mathrm{Ba}+{ }^{87} \mathrm{Sr}$, or $(d)$ saline control solution, reared for 30 days from 1 day posthatch.
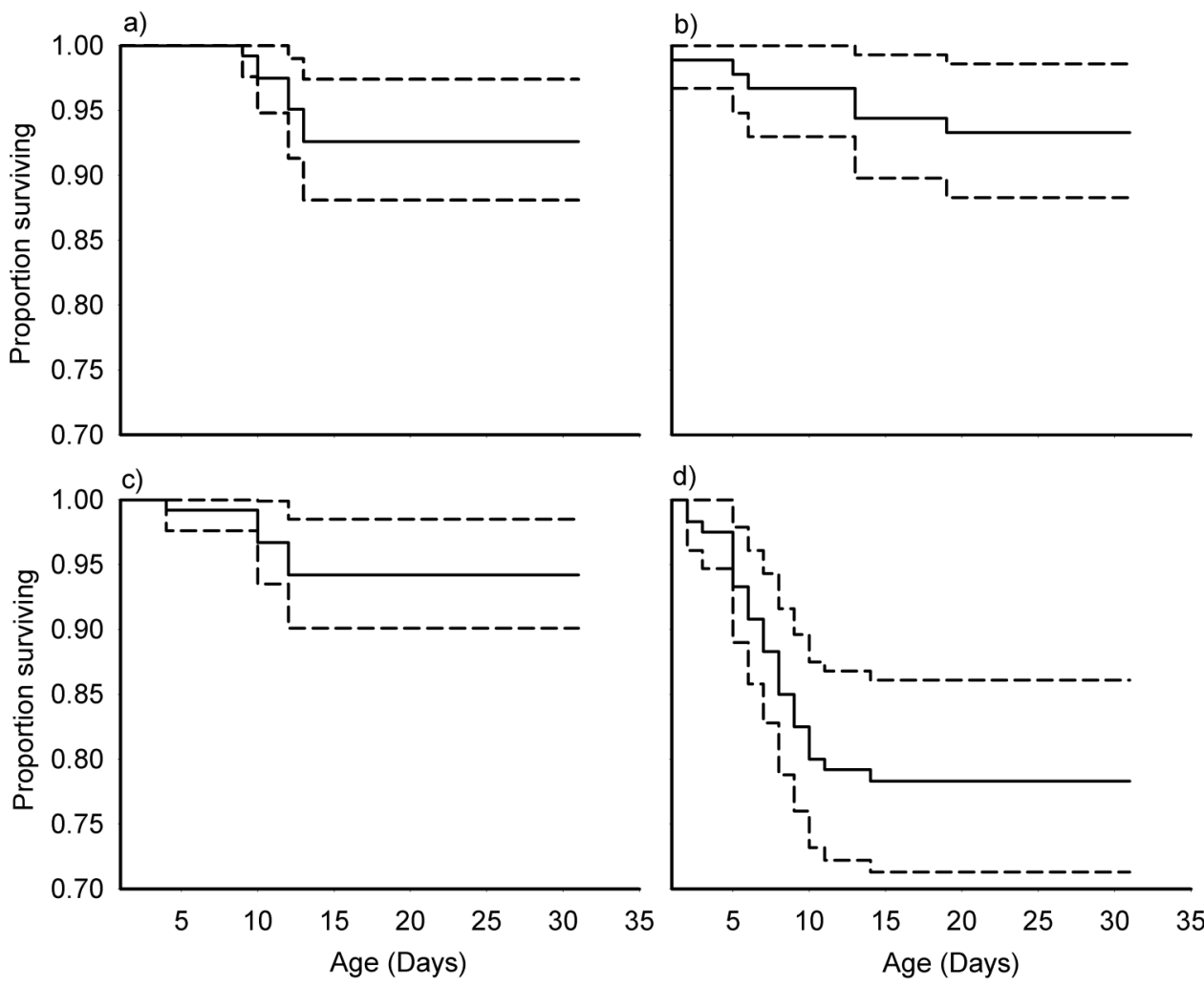

d)

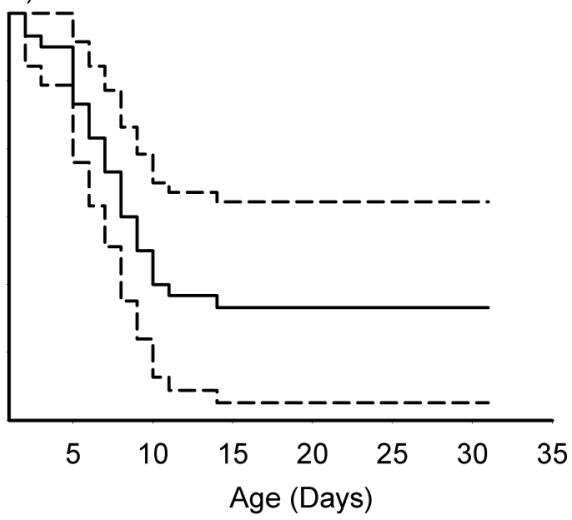

Table 2. Mixed effects Cox proportional-hazards model of survival of juvenile $M$. adspersa (31 days posthatch) from females injected with ${ }^{137} \mathrm{Ba},{ }^{87} \mathrm{Sr},{ }^{137} \mathrm{Ba}+{ }^{87} \mathrm{Sr}$, or a saline control.

\begin{tabular}{lllll}
\hline Fixed factor & Coefficient & SE & $Z$ & $P$ \\
\hline Treatment & & & & \\
Ba & 0.322 & 0.79 & -1.43 & 0.15 \\
$\mathrm{Sr}$ & 0.363 & 0.71 & -1.43 & 0.15 \\
$\mathrm{Ba}+\mathrm{Sr}$ & 0.278 & 0.74 & -1.74 & 0.08 \\
\hline Random factor & Variance & & & \\
\hline Female-Tub & 0.350 & & & \\
Female & 0.538 & & & \\
\hline
\end{tabular}

Note: Coefficients show the proportional change in survival, relative to the control treatment.

Of the 79 M. adspersa otoliths analysed, $62(78.4 \%)$ showed a typical spike in ${ }^{55} \mathrm{Mn}$ indicating successful ablation of the otolith core. Enriched stable isotope analysis of M. adspersa otoliths revealed large differences in ${ }^{138} \mathrm{Ba} /{ }^{137} \mathrm{Ba}$ and ${ }^{88} \mathrm{Sr} /{ }^{87} \mathrm{Sr}$ isotope ratios

Table 3. Linear mixed effects model of total length of juvenile M. adspersa from females injected with ${ }^{137} \mathrm{Ba}$, ${ }^{87} \mathrm{Sr},{ }^{137} \mathrm{Ba}+{ }^{87} \mathrm{Sr}$, or a saline control (Treatment).

\begin{tabular}{llll}
\hline Fixed factor & df & $\chi^{2}$ & $P$ \\
\hline Treatment & 3 & 2.07 & 0.56 \\
\hline Random factor & Variance & & \\
\hline Female-Tub & 0.117 & & \\
Female & 0.000 & & \\
Residual & 1.244 & & \\
\hline
\end{tabular}

Note: $\chi^{2}$ statistics are type II Wald tests of analysis of deviance.

between treatment groups (Fig. 4). Firstly, the ${ }^{138} \mathrm{Ba} /{ }^{137} \mathrm{Ba}$ isotope ratio of control otoliths $(6.07 \pm 0.07 \mathrm{SE}, n=20)$ was significantly different from the expected natural isotope ratio of 6.38 ( $t$ test, $\left.t_{19}=-4.38, P<0.001\right)$, suggesting weak $(\sim 5 \%)$ contamination with enriched ${ }^{137} \mathrm{Ba}$. However, the ${ }^{88} \mathrm{Sr} /{ }^{87} \mathrm{Sr}$ isotope ratio of control otoliths was $11.62 \pm 0.07(n=20)$ and was not significantly different from the expected natural isotope ratio of 11.5 ( $t$ test, $t_{19}=0.93$, 
Fig. 3. Box and whisker plot of total length ( $\mathrm{mm})$ of juvenile M. adspersa from females injected with ${ }^{137} \mathrm{Ba},{ }^{87} \mathrm{Sr},{ }^{137} \mathrm{Ba}+{ }^{87} \mathrm{Sr}$, or a saline control, reared for 30 days from 1 day posthatch. Solid dots represent individuals outside of 5\% and $95 \%$ quantiles.

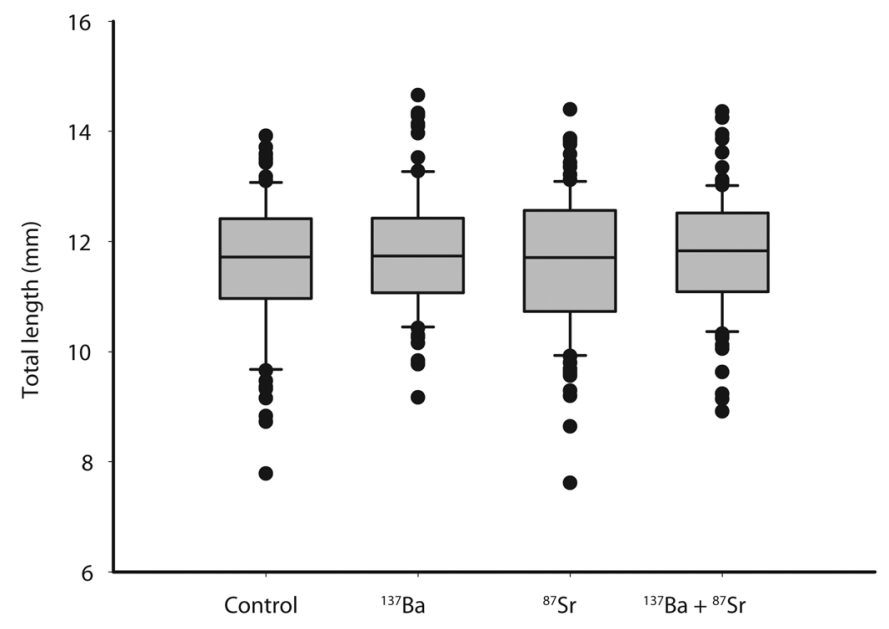

$P=0.36$ ). The mean ${ }^{138} \mathrm{Ba} /{ }^{137} \mathrm{Ba}$ isotope ratio for otoliths from the ${ }^{137} \mathrm{Ba}$ treatment group was $2.09 \pm 0.32(n=19)$, while the ${ }^{88} \mathrm{Sr} /{ }^{87} \mathrm{Sr}$ isotope ratio for otoliths from the ${ }^{87} \mathrm{Sr}$ treatment group was $1.37 \pm$ $0.1(n=20)$. The ${ }^{138} \mathrm{Ba} /{ }^{137} \mathrm{Ba}$ and ${ }^{88} \mathrm{Sr} /{ }^{87} \mathrm{Sr}$ isotope ratios for otoliths from the ${ }^{137} \mathrm{Ba}+{ }^{87} \mathrm{Sr}$ treatment group were $1.62 \pm 0.27$ and $0.93 \pm$ $0.17(n=20)$, respectively. Applying a rule of mean control ${ }^{138} \mathrm{Ba} /$ ${ }^{137} \mathrm{Ba}-2 \mathrm{SD},{ }^{88} \mathrm{Sr} /{ }^{87} \mathrm{Sr}-2 \mathrm{SD}$, and ${ }^{138} \mathrm{Ba} /{ }^{137} \mathrm{Ba}-2 \mathrm{SD}+{ }^{88} \mathrm{Sr} /{ }^{87} \mathrm{Sr}-$ 2 SD resulted in the classification of $100 \%$ of otoliths to their correct treatment group (Fig. 4).

\section{Meta-analysis of effects of transgenerational marking across species}

A meta-analysis of eight independent effect sizes extracted from four studies revealed a positive but nonsignificant effect of injected enriched stable barium isotopes on morphological traits at hatch (mean $g=0.031,95 \%$ confidence interval (CI): -0.199 to 0.26) (Fig. 5a; Table 4). However, there was significant amongstudy heterogeneity in effect sizes $\left(I^{2}=52.27 \%\right)\left(Q_{7}=14.17, P<0.04\right)$. Two studies on marine species (Amphiprion percula and Epinephelus fuscoguttatus) tended to show nonsignificant negative effects (Fig. 5a). Conversely, the two tropical freshwater fish species (Melanotaenia splendida and M. adspersa) showed positive effects, with some being significant in M. splendida (Fig. 5a). A meta-regression with dose included as a moderator variable showed a significant positive effect, suggesting that higher doses increase larval size (coefficient $=0.018$, 95\% CI: 0.004-0.031) (Table 4). Furthermore, there was a nonsignificant amount of heterogeneity $\left(\mathrm{QE}_{6}=7.07, P=0.31\right)$, suggesting that dose alone explained most of the variance between studies.

Five effect size estimates drawn from four studies of injected strontium showed no significant impacts of enriched stable strontium isotopes or $\mathrm{SrCl}_{2}$ on fish larvae morphology (mean $g=0.32$, 95\% CI: -0.344 to 0.973 ) (Fig. $5 b$, Table 4 ). Study effect size did not vary over the narrow range of doses (20-60 $\left.\mu \mathrm{g} \cdot \mathrm{g}^{-1}\right)$ examined in these studies (coefficient $=0.021,95 \%$ CI: -0.068 to 0.026 ) (Table 4 ). A significant amount of residual heterogeneity remained $\left(Q_{3}=\right.$ $24.35, P<0.001$ ), suggesting that other study-level differences may be contributing to the variation in effect sizes. For instance, a study on $M$. splendida showed significant positive effects of enriched stable strontium isotopes, while studies on Hypomesus transpacificus, Sebastes auriculatus, and M. adspersa (current study) showed no significant effects.

Overall, there was a significant negative effect of enriched barium isotope labelling on larval growth, derived from 11 effect sizes of growth from three studies (mean $g=-0.511,95 \% \mathrm{CI}$ : -0.972 to
Fig. 4. Mean $\pm \mathrm{SD}^{138} \mathrm{Ba} /{ }^{137} \mathrm{Ba}$ and ${ }^{88} \mathrm{Sr} /{ }^{87} \mathrm{Sr}$ isotope ratios of 79 otoliths sampled from control $(\bullet),{ }^{137} \mathrm{Ba}(\bigcirc),{ }^{87} \mathrm{Sr}(\boldsymbol{\nabla})$, and ${ }^{137} \mathrm{Ba}+$ ${ }^{87} \mathrm{Sr}(\Delta)$ treatment groups of $M$. adspersa larvae at 8-12 days posthatch. The natural ${ }^{138} \mathrm{Ba} /{ }^{137} \mathrm{Ba}$ and ${ }^{88} \mathrm{Sr} /{ }^{87} \mathrm{Sr}$ isotope ratios and the natural ratio -2 standard deviations, calculated from the control otoliths $(n=20)$, are represented by dashed and dotted lines, respectively.

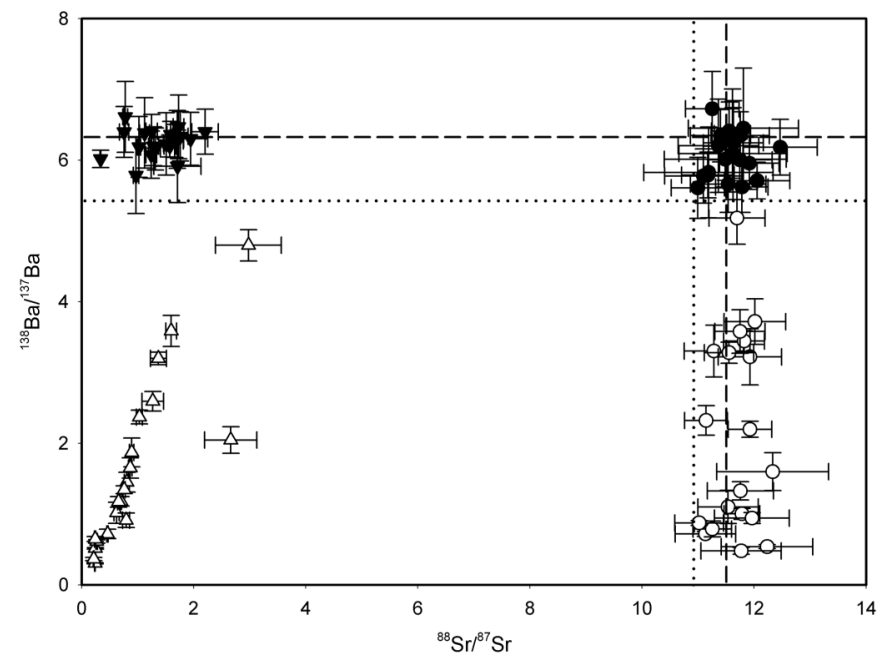

0.051) (Fig. 5c; Table 4). There was a significant amount of betweenstudy heterogeneity $\left(I^{2}=93.36 \% ; Q_{10}=107.3, P<0.001\right)$, but a leave-one-out analysis found that removal of any one of the three most negative effect sizes produced an overall effect size that was nonsignificant, suggesting that the result is not particularly robust, and that more studies are required to confirm this effect. Two marine and one freshwater fish species were represented in this analysis. Some significant negative growth effects were detected in A. percula and E. fuscoguttatus, but M. adspersa in the current study showed a nonsignificant effect of enriched stable barium marking on growth (Fig. 5c). Meta-regression with age postinjection and dose as moderator variables both singly and together found no significant relationship between either of these moderator variables and effect size (Table 4).

Finally, injected enriched stable strontium isotopes and $\mathrm{SrCl}_{2}$ produced a nonsignificant positive effect on growth (mean $g=$ 0.259 , 95\% CI: -0.18 to 0.70 ) (Fig. $5 d$; Table 4). Four species were represented in this meta-analysis, with a total of 17 effect sizes present. There was significant between-study heterogeneity $\left(I^{2}=\right.$ 97.2\%; $\left.Q_{13}=324.6, P<0.0001\right)$, but the nonsignificance of the overall estimate was not sensitive to the inclusion or exclusion of any one of these effect sizes. Effects were highly variable, with a significant negative growth effect present in $\mathrm{H}$. transpacificus and nonsignificant negative effects through to significant positive growth effects present in Oncorhynchus mykiss and Salmo trutta (Fig. $5 d$ ). Meta-regression revealed that age posthatch, dose, and dose + age posthatch were nonsignificant predictors of the variation in effect sizes between studies (Table 4).

\section{Discussion}

A thorough understanding of early life history ecology is critical to our understanding of fish recruitment dynamics and population replenishment (Sale 2002). The small size and fragility of young fishes poses a technical hurdle to marking and subsequent tracking of the movements and fate of individuals within their natural environment. Chemical marking techniques such as transgenerational marking, as well as genetic tools and otolith microchemistry analysis, all hold great promise for revolutionizing our understanding of fish population dynamics. While techniques that directly mark individuals may provide high resolv- 
Fig. 5. Forest plots of standardized effect sizes (Hedges' $g$ ) $\pm 95 \%$ confidence intervals of (a) composite morphological trait measurements of larvae from transgenerational marking studies with enriched stable barium isotopes, $(b)$ composite morphological trait measurements of larvae from transgenerational marking studies with enriched stable strontium isotopes or $\mathrm{SrCl}_{2},(c)$ effects of transgenerational marking with enriched stable barium isotopes on growth rates, and $(d)$ effects of transgenerational marking with either enriched stable strontium isotopes or $\mathrm{SrCl}_{2}$ on growth rates. Dose of isotopes injected into females ( $\mu \mathrm{g} \cdot \mathrm{g}^{-1}$ female body mass) and the element injected are also presented. Random effect metaanalytic mean effect size $\pm 95 \%$ confidence interval (RE Model) is shown at the bottom of each panel. Vertical dotted lines indicate zero (no effect).

a)

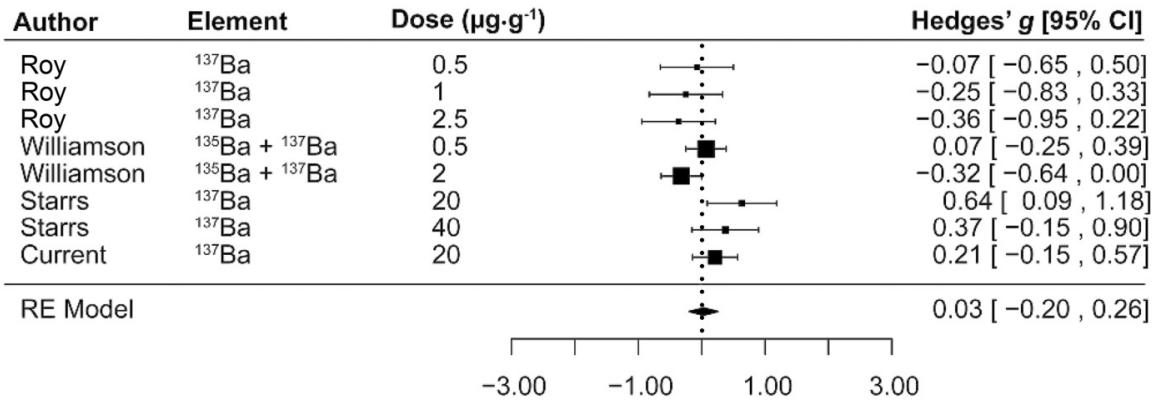

b)

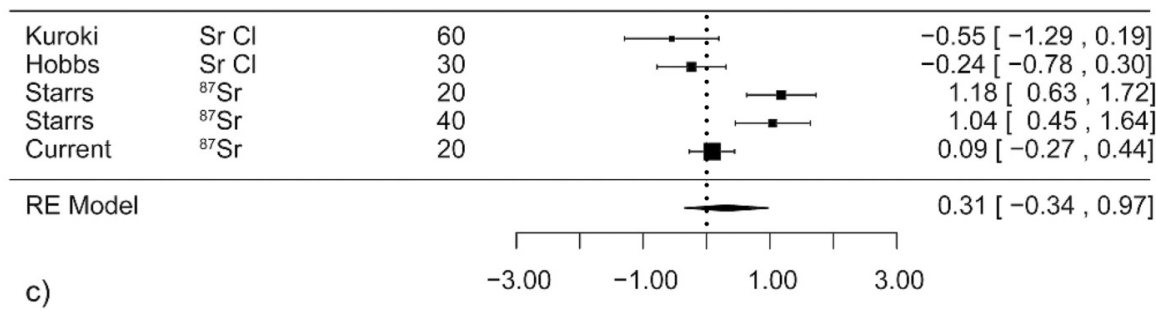

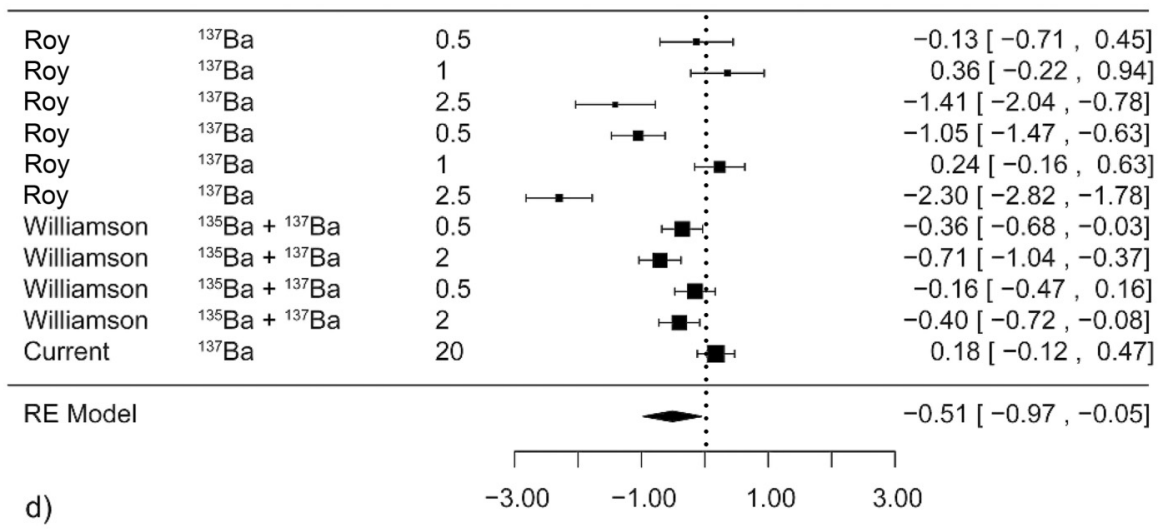

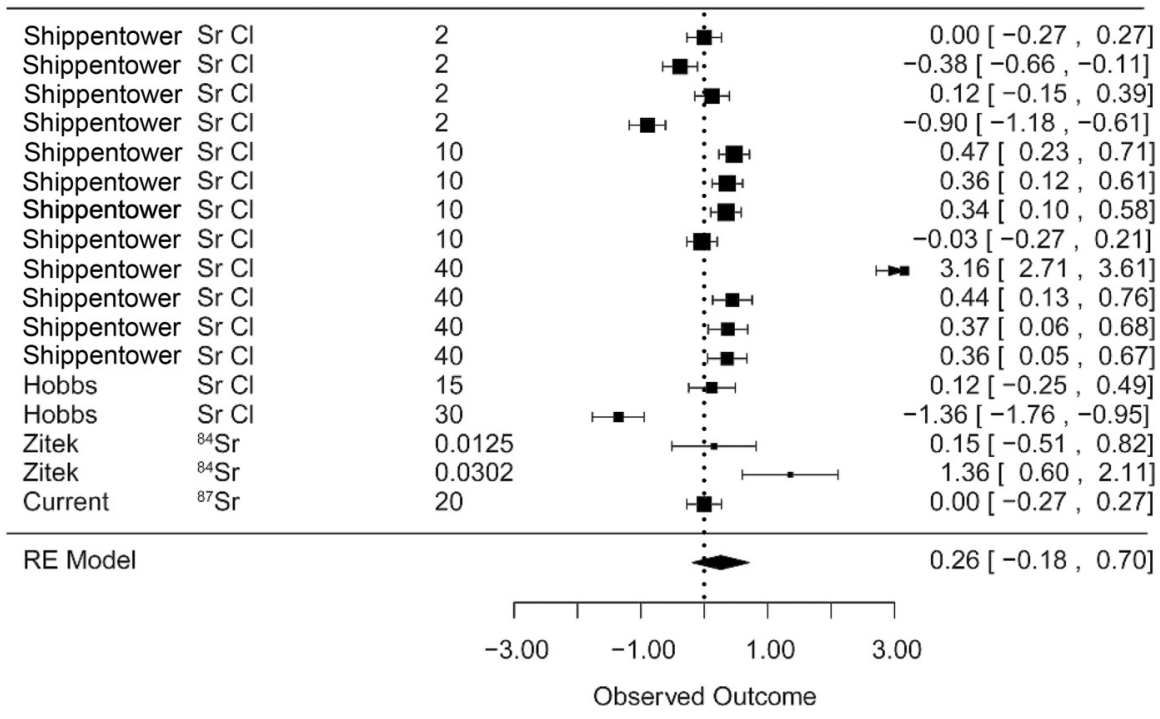




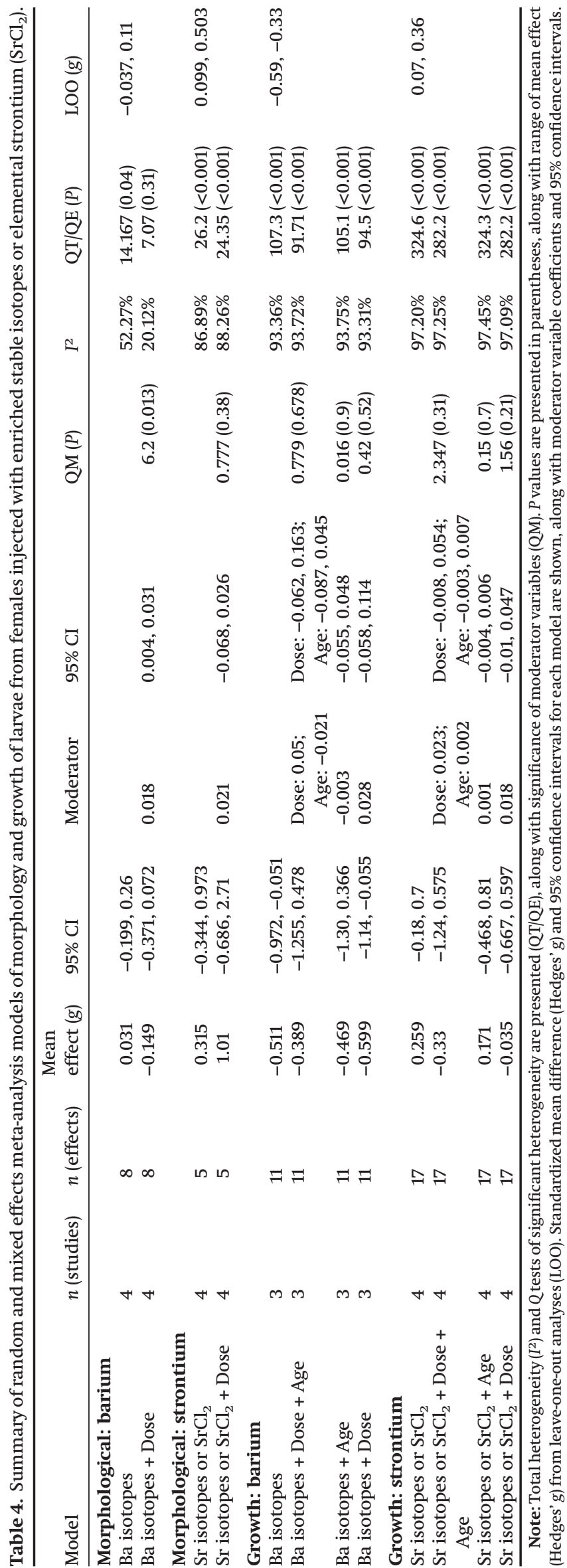

ing power, especially at small spatial and temporal scales, the assumptions that marking has no effect on marked individuals requires closer examination. It has been established in multiple taxa that exposure to high quantities of barium and strontium can have lethal effects (Dietz et al. 1992; Morohashi et al. 1994; Koch et al. 2003); however, the sublethal effects of minute doses of these elements have yet to be thoroughly evaluated. In the present study, we found that the effects of transgenerational marking with $20-40 \mu \mathrm{g} \cdot \mathrm{g}^{-1}$ of enriched stable ${ }^{137} \mathrm{Ba}$ and ${ }^{87} \mathrm{Sr}$ on larvae of M. adspersa varied among morphological traits, growth, and survival. Furthermore, meta-analysis of several studies revealed that the effects of transgenerational marking on larval morphology and growth are variable within and between species. Here, we will discuss the broader implications of our findings and future research directions in this growing field of research.

\section{Efficacy and impacts of transgenerational marking on larvae of $M$. adspersa}

Injecting female M. adspersa with enriched ${ }^{137} \mathrm{Ba},{ }^{87} \mathrm{Sr}$, or a combination of both isotopes successfully produced indelible marks in the core region of sagittal otoliths of subsequent offspring. Weak contamination (5\%) of control fish with ${ }^{137} \mathrm{Ba}$ is believed to have occurred from fish sharing the same high-density foam restraint during the injection process, leading to cross-contamination with enriched stable isotope solution. We analysed the second sagittal otolith of the control larvae $(n=20)$ and obtained the same results, confirming that contamination was the likely source of error (D. Starrs, unpublished data). Despite this minor issue, which can be avoided in future, $100 \%$ discrimination was possible between treatment groups, thereby establishing the efficacy of transgenerational marking with combined enriched strontium and barium isotopes to produce multiple batch markers. Furthermore, the impacts of transgenerational marking on subsequent larvae were minimal, with no significant observable impacts on SL and eyeball diameter at hatch or on growth at 31 days posthatch. Survival was not significantly different among treatment groups at 31 days posthatch. However, body depth at hatch was significantly reduced postinjection in larvae marked with enriched stable ${ }^{87} \mathrm{Sr}$ or ${ }^{137} \mathrm{Ba}+{ }^{87} \mathrm{Sr}$. Unfortunately, little is known about the impacts of barium and strontium on fish. Williamson et al. (2009b) found that injecting adult leopard coral grouper (Plectropomus leopardus) with $4 \mu \mathrm{g} \cdot \mathrm{g}^{-1}$ of enriched ${ }^{137} \mathrm{Ba}$ resulted in levels of ${ }^{137} \mathrm{Ba}$ in muscle tissue well below those expected to cause health issues in humans and had minimal impacts on physiological stress. Without knowing the specific mechanisms through which sublethal impacts of minute doses of barium and strontium isotopes may be expressed, we advocate careful exploration of potential impacts on readily measured traits that are presumed or known to be fitness indicators. Despite this, transgenerational marking provides a powerful and effective tool for mass-marking M. adspersa larvae, with considerable potential to explore early life history ecology and recruitment processes.

There were no significant impacts of transgenerational marking on the growth of M. adspersa larvae over 31 days posthatch in the current study. Larval growth rates were highly variable among individuals, with the largest larva being double the size of the smallest after 31 days. The average TL $(11.68 \mathrm{~mm})$ was less than that recorded in a previous study in which larvae were reared individually under variable food and temperature regimes (Starrs et al. 2013). However, the range of growth rates observed in the two studies was comparable. This suggests that competitive interactions may have been present within tubs and would increase with age as size discrepancies become greater, allowing aggression and cannibalism to shape survivorship and growth trajectories. It must be noted that all studies to date have been conducted in relatively benign lab-based environments that may be conducive to high levels of growth and survival compared with natural environments (Einum and Fleming 1999). After accounting for 
random effects, the nonsignificant treatment effect on survival in the mixed effects Cox proportional-hazards model suggests that transgenerational marking does not affect survival of $M$. adspersa larvae. We conclude that growth and survival of larval M. adspersa to 31 days posthatch were not affected by transgenerational marking in the current study.

Subtle shifts in larval morphological traits may come under strong selective pressure and have significant fitness consequences during early life history phases (Searcy and Sponaugle 2001; Vigliola and Meekan 2002). However, selective pressures can vary spatially, temporally, and throughout ontogeny (Gagliano et al. 2007), making identification of declines in mean trait values difficult to interpret. An alternative approach may be to examine changes in trait variability rather than changes in mean trait values per se, as variation is crucial for selection and may be adaptive in unpredictable environments (Marshall et al. 2008; Morrongiello et al. 2012). In the current study, there were no significant changes in variance of morphological trait values or growth, with the exception of body depth at hatch, pre- to postinjection. To what extent a reduction in mean body depth at hatch and variance may affect fitness is unknown. However, body depth correlates with swimming performance in larval fish (Fisher and Hogan 2007) and could also influence rates of predation by interacting with predators' perception of prey size (Endler 1986; Wainwright and Bellwood 2002). Further research is required to explore the fitness consequences of larval morphology at hatch to clarify the importance of such marking effects for study design and interpretation.

\section{Impacts of transgenerational marking across fish species}

Meta-analyses can underpin synthesis across multiple studies in the field of evolution and ecology (Osenberg et al. 1999; Koricheva et al. 2013), yet the degree of between-study variation tends to be high because of inherent variability between studies (Osenberg et al. 1999). Indeed, the current study found that maternal effects can have considerable impacts on effect size estimates. With mixed effects models, we found that body depth was significantly reduced in larvae exposed to ${ }^{87} \mathrm{Sr}$ and ${ }^{137} \mathrm{Ba}+{ }^{87} \mathrm{Sr}$ isotopes. However, use of the statistic Hedges' $g$, calculated from the difference between the mean trait value of the control group and each treatment group, does not take into account preinjection differences in traits across treatments. A similar effect was observed in a recent study on another freshwater fish, M. splendida (Starrs et al. in press). This highlights a limitation of extracting effect sizes from "after" only experiments, and the importance of quantifying "before" treatment variability (Osenberg et al. 1994). While extracting effect sizes from mixed effects models is possible (Nakagawa and Cuthill 2007), we did not use this approach because it would have rendered our estimates incomparable to effect sizes extracted from previously published studies, in which only mean trait values between treatment groups postinjection are presented. We advocate for future studies to examine trends in both the mean and variance of traits, both before and after injection, to increase statistical power in the detection of any sublethal transgenerational marking effects.

While the impacts of transgenerational marking appear to vary between species, the effects covary with each study (reflected in the high rate of among-study heterogeneity) so that untangling the effects of transgenerational marking on individual species from study-level differences in methods is confounded. Early indications are that marine species (A. percula and E. fuscoguttatus) tended to show negative effects of transgenerational marking, whereas studies on freshwater species (M. splendida, S. trutta, and M. adspersa) tended to find more positive effects in relation to larval morphology and growth. To what extent this is driven by study-level differences in method or phylogenetic effects remains unknown. The neutral effect of enriched barium isotopes across four studies suggests that doses within the range of $0.5-40 \mu \mathrm{g} \cdot \mathrm{g}^{-1}$ have no significant impacts on larval morphology. Conversely, enriched stable strontium isotopes and $\mathrm{SrCl}_{2}$ produced a stronger postive (albeit insignificant) effect on larval morphology at hatch. Given that this result was driven by two effect sizes from a single study on $M$. splendida, we urge caution in drawing conclusions from this result. Instead, we suggest that further research is required to determine whether strontium used in transgenerational marking affects larval morphology.

Dose of enriched stable barium isotopes was found to be a significant predictor of growth effects on fish larvae; however, the positive effect of dose is counterintuitive. It is noted that those studies applying the higher doses $\left(20-40 \mu \mathrm{g} \cdot \mathrm{g}^{-1}\right)$ were conducted on freshwater species, while the lower doses were used in studies on marine species. As such, this result may be driven by phylogenetic effects rather than true dose effects. The age at which larvae or juveniles were sampled was found to be nonsignificant, and neither dose nor age was significant in explaining the variation in growth effect sizes in studies applying enriched stable strontium isotopes or $\mathrm{SrCl}_{2}$. We hypothesize that lifetime growth trajectories may be influenced by maternal effects in response to the presence of enriched isotopes, or the enriched isotopes may impact upon developmental trajectories during embryogenesis. It has been found repeatedly that maternal influences decrease over time (Green 2008; Donelson et al. 2009); hence maternal influences are more likely to be observed during early ontogeny, which would lead to a weakening in effect size with fish age. Williamson et al. (2009a) examined larval growth of E. fuscoguttatus up to 3 days posthatch and detected small but significant negative effects, as did Roy (2008) in larvae of A. percula. Altogether, it appears that growth rates of some marine species may be negatively impacted by enriched stable barium isotope injections; however, the mechanism causing this result is unknown. Previous studies have found no physiological effects of transgenerational marking on female stress levels (Williamson et al. 2009b; Roy et al. 2013) at low doses ( $2 \mu \mathrm{g} \cdot \mathrm{g}^{-1}$ body mass) of enriched stable barium isotopes. Hence the role of maternal effects is unclear and additional studies examining lifelong fitness consequences of transgenerational marking are needed. Such studies ideally should focus on the possible impacts on reproductive output, through both direct (impacts on sex ratios, fertility) and indirect effects (growth rate, maximum size).

\section{Implications for future studies}

An important source of variation in morphological traits of day-of-hatch larvae was found among females and between clutches within females. This suggests that there are strong maternal influences on larval morphological traits, and indeed this is a well-known phenomenon (reviewed in Green 2008). In the current study, maternal identity explained $44 \%-68 \%$ of variability in larval morphological traits, demonstrating the importance of considering maternal effects in studies exploring day-of-hatch traits, particularly if a range of female sizes are used within each treatment group (Benoît and Pepin 1999; Green 2008). Likewise, maternal identity was found to explain $10.5 \%-33.9 \%$ of variation in M. splendida larval morphology at hatch (Starrs et al. in press). This highlights a need to collect extensive data on larvae prior to injection, as maternal effects may lead to erroneous conclusions regarding the impacts of transgenerational marking on larval morphology. Higher replication at the female level per treatment may help to alleviate the influence of maternal effects on measured larval traits, allowing for a more precise evaluation of treatment-level effects. Future studies should aim to quantify or control for maternal effects when examining the impacts of transgenerational marking on larvae.

We note that, to date, relevant studies including this one have focussed on morphological and ontogenetic traits, while the behaviour of larvae in response to transgenerational marking has been neglected. Behaviour is a critical aspect of early life history 
ecology, influencing individual survivorship (Leis and McCormick 2002; Fuiman et al. 2006). Incorporating studies examining morphological, physiological, ontogenetic, and behavioural responses to transgenerational marking via the meta-analysis approach may provide the best means of identifying the impacts of transgenerational marking on larvae when individual studies lack sufficient statistical power. Meta-analysis was previously applied to identify the adverse effects of toe-clipping in anurans when the statistical power of individual studies was insufficient to identify negative effects (McCarthy and Parris 2004). We anticipate that in the future, an increased number of relevant studies combined with meta-analysis will lead to clearer resolution of transgenerational marking effects on fish larvae generally and with regard to phylogeny.

\section{Acknowledgements}

We thank Ty Starrs and Lora Jensen for assistance with fish husbandry. Les Kinsley and Graham Mortimer proved assistance with LA-ICPMS and preparation of enriched stable isotope spikes. We thank Dave Williamson for providing raw data from his paper for us to estimate effect sizes and Michael Jennions for providing critical feedback on an earlier version of the manuscript. Two anonymous reviewers provided constructive feedback that improved the manuscript. Funding was provided by the Australian Society for Fish Biology and the Linnean Society of New South Wales. Ethics approval was provided by the Australian National University Animal Experimental Ethics Committee, protocols Nos. R.BSB.04.10 and A2012/40.

\section{References}

Abràmoff, M.D., Magalhães, P.J., and Ram, S.J. 2004. Image processing with Image J. Biophoton. Int. 11: 36-42.

Almany, G.R., Berumen, M.L., Thorrold, S.R., Planes, S., and Jones, G.P. 2007. Local replenishment of coral reef fish populations in a marine reserve. Science, 316: 742-744. doi:10.1126/science.1140597. PMID:17478720.

Bates, D., Maechler, M., and Bolker, B. 2011. Linear mixed-effects models using S4 classes [online]. Available from http://lme4.r-forge.r-project.org/ [accessed 22 July 2013].

Benoît, H., and Pepin, P. 1999. Interaction of rearing temperature and maternal influence on egg development rates and larval size at hatch in yellowtail flounder (Pleuronectes ferrugineus). Can. J. Fish. Aquat. Sci. 56(5): 785-794. doi: 10.1139/f98-213.

Berumen, M.L., Walsh, H.J., Raventos, N., Planes, S., Jones, G.P., Starczak, V., and Thorrold, S.R. 2010. Otolith geochemistry does not reflect dispersal history of clownfish larvae. Coral Reefs, 29: 883-891. doi:10.1007/s00338-010-0652-z.

Brophy, D., Jeffries, T.E., and Danilowicz, B.S. 2004. Elevated manganese concentrations at the cores of clupeid otoliths: possible environmental, physiological, or structural origins. Mar. Biol. 144: 779-786. doi:10.1007/s00227-0031240-3.

Cooke, S.J., Midwood, J.D., Thiem, J.D., Klimey, P., Lucas, M.C., Thorstad, E.B., Eiler, J., Holbrook, C., and Ebner, B.C. 2013. Tracking animals in freshwater with electronic tags: past, present and future. Anim. Biotelem. 1: 1:19. doi:10. 1186/2050-3385-1-5.

Del Re, A.C. 2012. Package "compute.es" [online]. Available from http:// cran.rproject.org/package=compute.es [accessed 22 July 2013]

Dietz, D.D., Elwell, M.R., Davis, W.E., and Meirhenry, E.F. 1992. Subchronic toxicity of barium chloride dihydrate administered to rats and mice in the drinking water. Fund. Appl. Toxicol. 19: 527-537. doi:10.1016/0272-0590(92) 90091-U. PMID:1426711.

Donelson, J.M., Munday, P.L., and McCormick, M.I. 2009. Parental effects on offspring life histories: when are they important? Biol. Lett. 5: 262-265. doi: 10.1098/rsbl.2008.0642. PMID:19126532.

Eggins, S.M., Sadekov, A., and De Deckker, P. 2004. Modulation and daily banding of $\mathrm{Mg} / \mathrm{Ca}$ in Orbulina universa tests by symbiont photosynthesis and respiration: a complication for seawater thermometry? Earth Planet. Sci. Lett. 225: 411-419. doi:10.1016/j.epsl.2004.06.019.

Einum, S., and Fleming, I.A. 1999. Maternal effects of egg size in brown trout (Salmo trutta): norms of reaction to environmental quality. Proc. R. Soc. B Biol. Sci. 266: 2095-2100. doi:10.1098/rspb.1999.0893.

Endler, J.A. 1986. Natural selection in the wild. Princeton University Press, Princeton.

Fisher, R., and Hogan, J.D. 2007. Morphological predictors of swimming speed: a case study of pre-settlement juvenile coral reef fishes. J. Exp. Biol. 210: 24362443. doi:10.1242/jeb.004275. PMID:17601947.

Fox, J., Weisberg, S., Adler, D., Bates, D., Baud-Bovy, G., Ellison, S., Firth, D., Friendly, M., Gorjanc, G., Graves, S., Heiberger, R., Laboissiere, R., Monette, G.,
Murdoch, D., Nilsson, H., Ogle, D., Ripley, B., Venables, W., and Zeileis, A. 2013. Companion to applied regression [online]. Available from http://cran. r-project.org/web/packages/car/car.pdf [accessed 25 September 2013].

Fuiman, L.A., Rose, K.A., Cowan, J.H., Jr., and Smith, E.P. 2006. Survival skills required for predator evasion by fish larvae and their relation to laboratory measures of performance. Anim. Behav. 71:1389-1399. doi:10.1016/j.anbehav. 2005.11.013.

Gagliano, M., McCormick, M.I., and Meekan, M.G. 2007. Survival against the odds: ontogenetic changes in selective pressure mediate growth-mortality trade-offs in a marine fish. Proc. R. Soc. B Biol. Sci. 274: 1575-1582. doi:10. 1098/rspb.2007.0242.

Green, B.S. 2008. Maternal effects in fish populations. Adv. Mar. Biol. 54: 1-105. doi:10.1016/S0065-2881(08)00001-1. PMID:18929063.

Harrell F.E., Jr. 2001. Regression model strategies with applications to linear models, logistic regression and survival analysis. Springer, New York.

Huelga-Suarez, G., Moldovan, M., Garcia-Valiente, A., Garcia-Vazquez, E., and Garcia Alonso, J.I. 2012. Individual-specific transgenerational marking of fish populations based on a barium dual-isotope procedure. Analyt. Chem. 84: 127-133. doi:10.1021/ac201946k.

Jones, G.P., Milicich, M.J., Emslie, M.J., and Lunow, C. 1999. Self-recruitment in a coral reef fish population. Nature, 402: 802-804. doi:10.1038/45538.

Jones, G.P., Almany, G.R., Russ, G.R., Sale, P.F., Steneck, R.S., van Oppen, M.J.H., and Willis, B.L. 2009. Larval retention and connectivity among populations of corals and reef fishes: history, advances and challenges. Coral Reefs, 28: 307-325. doi:10.1007/s00338-009-0469-9.

Koch, M., Appoloni, O., Haufroid, V., Pharm, D., Vincent, J.L., and Lheureux, P. 2003. Acute barium intoxication and hemodiafiltration. J. Toxicol. Clin. Toxicol. 41: 363-367. doi:10.1081/CLT-120022004. PMID:12870878.

Koricheva, J., Gurevitch, J., and Mengersen, K. 2013. Handbook of meta-analysis in ecology and evolution. Princeton University Press, Princeton.

Leis, J.M., and McCormick, M.I. 2002. Ecology of the pelagic, larval stage of coral reef fishes. In Coral reef fishes: dynamics and diversity in a complex ecosystem. Edited by P.F. Sale. Academic Press, San Diego. pp. 171-199.

Macdonald, J.I., Shelley, J.M.G., and Crook, D.A. 2008. A method for improving the estimation of natal chemical signatures in otoliths. Trans. Am. Fish. Soc. 137: 1674-1682. doi:10.1577/T07-249.1.

Marshall, D.J., Bonduriansky, R., and Bussière, L.F. 2008. Offspring size variation within broods as a bet-hedging strategy in unpredictable environments. Ecology, 89(9): 2506-2517. doi:10.1890/07-0267.1. PMID:18831172.

McCarthy, M.A., and Parris, K.M. 2004. Clarifying the effect of toe clipping on frogs with Bayesian statistics. J. Appl. Ecol. 41: 780-786. doi:10.1111/j.00218901.2004.00919.x.

Morohashi, T., Sano, T., and Yamada, S. 1994. Effects of strontium on calcium metabolism in rats I. A distinction between pharmacological and toxic doses. Jpn. J. Pharmacol. 64: 155-162. doi:10.1254/jjp.64.155.

Morrongiello, J.R., Bond, N.R., Crook, D.A., and Wong, B.B.M. 2012. Spatial variation in egg size and egg number reflects trade-offs and bet-hedging in a freshwater fish. J. Anim. Ecol. 81: 806-817. doi:10.1111/j.1365-2656.2012.01961.x. PMID:22309288.

Munro, A.R., Gillanders, B.M., Elsdon, T.S., Crook, D.A., and Sanger, A.C. 2008. Enriched stable isotope marking of juvenile golden perch (Macquaria ambigua) otoliths. Can. J. Fish. Aquat. Sci. 65(2): 276-285. doi:10.1139/f08-010.

Munro, A.R., Gillanders, B.M., Thurstan, S., Crook, D.A., and Sanger, A.C. 2009. Transgenerational marking of freshwater fishes with enriched stable isotopes: a tool for fisheries management and research. J. Fish Biol. 75: 668-684. doi:10.1111/j.1095-8649.2009.02352.x. PMID:20738564.

Nakagawa, S., and Cuthill, I.C. 2007. Effect size, confidence interval and statistical significance: a practical guide for biologists. Biol. Rev. 82: 591-605. doi:10.1111/j.1469-185X.2007.00027.x. PMID:17944619.

Nakagawa, S., and Schielzeth, H. 2010. Repeatability for Gaussian and nonGaussian data: a practical guide for biologists. Biol. Rev. 85: 935-956. doi:10. 1111/j.1469-185X.2010.00141.x. PMID:20569253.

Osenberg, C.W., Schmitt, R.J., Holbrook, S.J., Abu-Saba, K.E., and Flegal, A.R. 1994. Detection of environmental impacts: natural variability, effect size, and power analysis. Ecol. Appl. 4: 16-30. doi:10.2307/1942111.

Osenberg, C.W., Sarnelle, O., Cooper, S.D., and Holt, R.D. 1999. Ecological questions through meta-analysis: goals, metrics, and models. Ecology, 80: 11051117. doi:10.1890/0012-9658(1999)080[1105:REQTMA]2.0.CO;2.

Pangle, K.L., Ludsin, S.A., and Fryer, B.J. 2010. Otolith microchemistry as a stock identification tool for freshwater fishes: testing its limits in Lake Erie. Can. J. Fish. Aquat. Sci. 67(9): 1475-1489. doi:10.1139/F10-076.

Pusey, B.J., Kennard, M.J., and Arthington, A.H. 2004. Freshwater fishes of northeastern Australia. CSIRO Publishing, Melbourne.

R Development Core Team. 2011. R: a language and environment for statistical computing. Vienna, Austria.

Roddick, J.C., and Compston, W. 1977. Strontium isotopic equilibration: a solution to a paradox. Earth Planet. Sci. Lett. 34: 238-246. doi:10.1016/0012821X(77)90008-5.

Rosman, K.J.R., and Taylor, P.D.P. 1998. Isotopic compositions of the elements 1997. Pure Appl. Chem. 70: 217-235. doi:10.1351/pac199870010217.

Roy, A.-S. 2008. Trans-generational marking of clownfish larvae via maternal transmission of stable isotopes. M.Sc., School of Marine and Tropical Biology, James Cook University, Townsville. 
Roy, A.-S., Frisch, A.J., Syms, C., Thorrold, S.R., and Jones, G.P. 2013. Retention of a transgenerational marker $\left({ }^{137}\right.$ Barium) in tissues of adult female anemonefish and assessment of physiological stress. Environ. Biol. Fishes, 96: 459466. doi:10.1007/s10641-012-0029-y.

Sale, P.F. 2002. Coral reef fishes: dynamics and diversity in a complex ecosystem. Academic Press, San Diego.

Searcy, S.P., and Sponaugle, S. 2001. Selective mortality during the larvaljuvenile transition in two coral reef fishes. Ecology, 82: 2452-2470. doi:10. $2307 / 2679928$.

Sinclair, D.J., Kinsley, L.P.J., and McCulloch, M.T. 1998. High resolution analysis of trace elements in corals by laser ablation ICP-MS. Geochim. Cosmochim. Acta, 62: 1889-1901. doi:10.1016/S0016-7037(98)00112-4.

Starrs, D., Ebner, B.C., and Fulton, C.J. 2013. Can backcalculation models unravel complex larval growth histories in a tropical freshwater fish? J. Fish Biol. 83: 96-110. doi:10.1111/jfb.12152. PMID:23808694.

Starrs, D., Ebner, B.C., Eggins, S.M., and Fulton, C.J. In press. Longevity in maternal transmission of isotopic marks in a tropical freshwater rainbowfish and the implications for offspring morphology. Mar. Freshw. Res. doi:10.1071/ MF13150.

Swearer, S.E., Caselle, J.E., Lea, D.W., and Warner, R.R. 1999. Larval retention and recruitment in an island population of a coral-reef fish. Nature, 402: 799802. doi: $10.1038 / 45533$.

Therneau, T. 2012. coxme: Mixed effects Cox models [online]. Available from http://r-forge.r-project.org [accessed 22 July 2013].

Thorrold, S.R., Jones, G.P., Planes, S., and Hare, J.A. 2006. Transgenerational marking of embryonic otoliths in marine fishes using barium stable isotopes. Can. J. Fish. Aquat. Sci. 63(6): 1193-1197. doi:10.1139/f06-048.

Viechtbauer, W. 2010. Conducting meta-analyses in R with the metafor package. J. Stat. Softw. 36: 1-49.
Vigliola, L., and Meekan, M.G. 2002. Size at hatching and planktonic growth determine post-settlement survivorship of a coral reef fish. Oecologia, 131: 89-93. doi:10.1007/s00442-001-0866-4.

Volk, E.C., Schroder, S.L., and Grimm, J.J. 1999. Otolith thermal marking. Fish. Res. 43: 205-219. doi:10.1016/S0165-7836(99)00073-9.

Wainwright, P.C., and Bellwood, D.R. 2002. Ecomorphology of feeding in coral reef fishes. In Coral reef fishes: dynamics and diversity in a complex ecosystem. Edited by P.F. Sale. Academic Press, San Diego. pp. 33-56.

Williamson, D.H., Jones, G.P., and Thorrold, S.R. 2009a. An experimental evaluation of transgenerational isotope labelling in a coral reef grouper. Mar. Biol. 156: 2517-2525. doi:10.1007/s00227-009-1276-0.

Williamson, D.H., Jones, G.P., Thorrold, S.R., and Frisch, A.J. 2009b. Transgenerational marking of marine fish larvae: stable-isotope retention, physiological effects and health issues. J. Fish Biol. 74: 891-905. doi:10.1111/j.1095-8649.2008. 02176.x. PMID:20735606.

Woodbury, A.M., Ricker, W.E., Cottam, C., Taber, R.D., and Pendleton, R.C. 1956. Symposium: Uses of marking animals in ecological studies. Ecology, 37: 665689. doi:10.2307/1933058.

Woodcock, S.H., Gillanders, B.M., Munro, A.R., Crook, D.A., and Sanger, A.C. 2011. Determining mark success of 15 combinations of enriched stable isotopes for the batch marking of larval otoliths. N. Am. J. Fish. Manage. 31(5): 843-851. doi:10.1080/02755947.2011.623760.

Woodcock, S.H., Grieshaber, C.A., Walther, B.D., and MacLatchy, D. 2013. Dietary transfer of enriched stable isotopes to mark otoliths, fin rays, and scales. Can. J. Fish. Aquat. Sci. 70(1): 1-4. doi:10.1139/cjfas-2012-0389.

Zitek, A., Irrgeher, J., Kletzl, M., Weismann, T., and Prohaska, T. 2013. Transgenerational marking of brown trout Salmo trutta f.f., using an ${ }^{84} \mathrm{Sr}$ spike. Fish. Manage. Ecol. 20: 354-361. doi:10.1111/fme.12018. 